\title{
PENGARUH PENGGUNAAN BERBAGAI JENIS KOMPOS TERHADAP KANDUNGAN HARA N, P, K ANDISOL DI KEBUN KOPI ARABIKA KECAMATAN TIMANG GAJAH KABUPATEN BENER MERIAH
}

\author{
(The Effect Uses Various Types of Compost on the Content of Andisol N, P, K Nutrients in the \\ Arabica Coffee Plantation, Timang Gajah District, Bener Meriah Regency)
}

\author{
Supriadi Supriadi ${ }^{1}$, Zuraida Zuraida ${ }^{1}$, Hifnalisa Hifnalisa ${ }^{1 *}$ \\ ${ }^{1}$ Program Studi Ilmu Tanah, Fakultas Pertanian, Universitas Syiah Kuala \\ *Corresponding author: hifnalisa@ unsyiah.ac.id
}

\begin{abstract}
Abstrak. Pertanian kopi organik didefinisikan sebagai sistem budidaya pertanian yang mengandalkan bahanbahan alami tanpa menggunakan bahan kimia sintesis. Permintaan pasar yang semakin meningkat terhadap kopi dikarenakan adanya perubahan pola hidup konsumen yang lebih mengutamakan kesehatan dan kelestarian lingkungan. Potensi kopi Arabika gayo dapat mencapai 3 ton ha ${ }^{-1}$ tahun $^{-1}$ jika dirawat dengan optimal, akan tetapi akibat dari pemahaman yang salah tanaman kopi Arabika di Bener Meriah hanya mampu berproduksi $700-800$ $\mathrm{kg} \mathrm{ha}^{-1}$. Umumnya kopi organik yang di budidayakan pada tanah Andisol juga memerlukan asupan nutrisi agar tanaman kopi dapat berproduksi optimal. Alternatif yang dapat digunakan adalah pemberian kompos yang dapat dibuat dengan memanfaatkan bahan-bahan yang ada di sekeliling kebun kopi. Bahan yang digunakan dalam penelitian ini berasal dari tumbuhan gulma Tithonia diversifolia, tumbuhan Lamtoro, dan limbah hasil pengolahan biji kopi. Penggunaan kompos dapat menggantikan peran pupuk anorganik dalam meningkatkan unsur hara sehingga asupan nutrisi dapat tercukupi untuk tanaman. Penelitian ini menggunakan Rancangan Acak Kelompok (RAK) non Faktorial dengan 3 ulangan dan terdiri dari 7 (tujuh) perlakuan sehingga terdapat 21 sampel tanah yang akan diamati dengan dosis kompos yang dipakai yaitu $12,5 \mathrm{~kg}_{\text {pohon }}^{-1}$. Perlakuan yang digunakan yaitu: Tanpa kompos, kompos T. diversifolia, kompos Lamtoro, kompos Kulit biji kopi, kompos T. diversifolia + Lamtoro, kompos T. diversifolia + Kulit biji kopi dan kompos Lamtoro + Kulit biji kopi. Penelitian ini dilaksanakan pada kebun percobaan Universitas Syiah Kuala, Desa Mekar Ayu, Kecamatan Timang Gajah, Kabupaten Bener Meriah dan di Laboratorium Penelitian Tanah dan Tanaman, Universitas Syiah Kuala. Parameter yang diamati adalah kandungan hara N, P, K. Perlakuan kompos yang diberikan pada tanaman kopi Arabika yang dibudidayakan pada tanah Andisol dapat meningkatkan kandungan hara yaitu: N-total, P-tersedia, K-dd. Perlakuan kompos terbaik yang mampu mensuplai hara lebih banyak pada tanah Andisol untuk tanaman kopi Arabika adalah perlakuan kompos T. diversifolia, sehingga kompos ini dapat di jadikan alternatif pengganti pupuk kimia.
\end{abstract}

Kata Kunci: Kompos, Kopi Arabika, Timang Gajah.

Abstract. Organic coffee farming is defined as an agricultural cultivation system that relies on natural ingredients
without using synthetic chemicals. The increasing market demand for coffee is due to changes in the lifestyle of
consumers who prioritize health and environmental sustainability. The potential of Gayo Arabica coffee can reach
3 tonnes ha $\mathrm{a}^{-1}$ year ${ }^{-1}$ if treated optimally, however as a result of the wrong understanding of Arabica coffee plants
in Bener Meriah can only produce $700-800 \mathrm{~kg} \mathrm{ha}^{-1}$. Generally, organic coffee cultivated on Andisol soil also
requires nutritional intake so that coffee plants can produce optimally. An alternative that can be used is the
provision of compost that can be made by utilizing the materials around the coffee garden. The materials used in
this study came from the weed Tithonia diversifolia, Lamtoro plants, and waste from the processing of coffee
beans. The use of compost can replace the role of inorganic fertilizers in increasing nutrients so that nutrient intake
can be fulfilled for plants. This study used a non-factorial randomized block design (RBD) with 3 replications and
consisted of 7 (seven) treatments so that there were 21 soil samples to be observed with the compost dose used,
namely $12.5 \mathrm{~kg}$ tree ${ }^{-1}$. The treatments used were: Without compost, T. diversifolia compost, Lamtoro compost,
coffee bean husk compost, T. diversifolia + Lamtoro compost, T. diversifolia compost + Coffee bean husk and
Lamtoro compost + Coffee bean husk. This research was conducted at the experimental garden of Syiah Kuala
University, Mekar Ayu Village, Timang Gajah District, Bener Meriah Regency and at the Soil and Plant Research
Laboratory, Syiah Kuala University. The parameters observed were nutrient content of N, P, K. Compost treatment
given to Arabica coffee plants cultivated on Andisol soil can increase the content of nutrients, namely: N-total, P-
available, K-dd. The best compost treatment that is able to supply more nutrients to Andisol soil for Arabica coffee
is the treatment of T. diversifolia compost, so that this compost can be used as an alternative to chemical fertilizers.

Keywords: Compost, Arabica Coffee, Timang Gajah. 


\section{PENDAHULUAN}

Kopi merupakan salah satu komoditi perdagangan dari sektor perkebunan yang memiliki potensi untuk dikembangkan dalam rangka usaha memperbesar pendapatan negara dan meningkatkan penghasilan pengusaha dan petani. Salah satu daerah penghasil utama kopi di Indonesia adalah Kabupaten Bener Meriah yang terletak di bagian tengah Provinsi Aceh. Komoditi kopi di Bener Meriah telah menjadi komoditi utama yang dihasilkan oleh perkebunan rakyat. Sekitar 70\% kopi Arabika di Kabupaten Bener Meriah telah mendapatkan sertifikat produk dengan landasan sistem pertanian berkelanjutan dikarenakan sebagian besar kebun kopi dikelolah secara organik. Sertifikasi yang diperoleh menempatkan posisi kopi asal dataran tinggi Gayo sebagai kopi organik terbaik di mata dunia (Disbun Provinsi Aceh, 2013).

Pertanian kopi organik didefinisikan sebagai sistem budidaya pertanian yang mengandalkan bahan-bahan alami tanpa menggunakan bahan kimia sintesis. Permintaan pasar yang semakin meningkat terhadap kopi dikarenakan adanya perubahan pola hidup konsumen yang lebih mengutamakan kesehatan dan kelestarian lingkungan. Masyarakat Bener Meriah mulai banyak yang beralih dari pertanian anorganik menjadi pertanian organik, tetapi masyarakat setempat mempunyai pemahanan yang berbeda tentang pertanian organik. Masyarakat beranggapan bahwa kopi organik yang di tanam pada tanah Andisol atau tanah yang terbentuk akibat letusan gunung berapi merupakan tanah yang subur dan kaya unsur hara, sehingga tanaman kopi tidak perlu dilakukan pemupukan. Potensi kopi Arabika gayo dapat mencapai 3 ton ha ${ }^{-1}$ tahun $^{-1}$ jika dirawat dengan optimal, akan tetapi akibat dari pemahaman yang salah tanaman kopi Arabika di Bener Meriah hanya mampu berproduksi $700-800 \mathrm{~kg} \mathrm{ha}$ 1 (Disbun Provinsi Aceh, 2013). Secara umum dalam bidang pertanian tanaman membutuhkan suplai hara dari luar untuk membantu pertumbuhan, perkembangan serta produksi yang akan dihasilkan. Salah satu alternatif pertanian organik untuk menyediakan unsur hara bagi tanaman yaitu dengan menggunakan pupuk kompos yang dapat dibuat dengan memanfaatkan bahan yang berada di sekitar perkebunan.

Penggunaan kompos bahan baku lokal merupakan tindakan yang sangat baik untuk dilakukan dalam menyediakan unsur hara bagi tanaman. Penggunaan bahan-bahan lokal dapat meningkatkan keefektifan dan efisiensi dalam bidang pertanian. Hal ini dikarenakan bahan untuk pembuatan pupuk kompos sangat mudah untuk diperoleh dan tidak membutuhkan biaya yang besar dalam pembuatannya. Bahan-bahan organik lokal yang dapat digunakan salah satunya adalah limbah-limbah hasil pertanian seperti limbah kulit kopi dan tanaman gulma yang berada di sekitar kebun (Fatmalasari et al., 2016). Penggunaan kompos lokal lebih bagus dibandingkan menggunakan bahan kompos yang berasal dari luar daerah. Bahan organik luar daerah pastinya memiliki kandungan unsur hara yang berbeda dibandingkan dengan bahan organik setempat.

Bahan baku pembuatan kompos di Kabupaten Bener Meriah sangat melimpah dan sangat berpotensi untuk dimanfaatkan menjadi pupuk organik. Bahan yang digunakan dalam penelitian ini berasal dari tumbuhan gulma Tithonia diversifolia, tumbuhan Lamtoro, dan limbah hasil pengolahan biji kopi. Bahan kompos yang digunakan sangat mudah untuk dicari dan dikumpulkan karena terdapat disekitaran kebun warga dan limbah kulit biji kopi sangat banyak terdapat di sekitaran pabrik. Penggunaan kompos dapat menggantikan peran pupuk anorganik dalam meningkatkan unsur hara sehingga asupan nutrisi dapat tercukupi untuk tanaman. 


\section{METODE PENELITIAN}

Penelitian ini merupakan eksperimen lapangan yang dilaksanakan pada kebun percobaan Universitas Syiah Kuala, Desa Mekar Ayu, Kecamatan Timang Gajah, Kabupaten Bener Meriah sejak bulan Juni sampai Desember 2020, kemudian dilanjutkan dengan analisis tanah di laboratorium Penelitian Tanah dan Tanaman, Universitas Syiah Kuala, Banda Aceh.

Penelitian ini menggunakan alat-alat berupa GPS (Global Possitioning System), parang, karung, terpal plastik, garu, ember, cangkul, bor tanah, timbangan analitik, oven, shaker, spektrofotometer, AAS (Atomic Absorption Spectrophotometer), alat destilasi, neraca analitik dan peralatan gelas. Bahan yang digunakan dalam penelitian ini adalah tanah Andisol pada kebun kopi arabika berumur 8 tahun, pangkasan Tithonia diversifolia, pangkasan lamtoro, kulit biji kopi, EM4, Aquades, $\mathrm{H}_{2} \mathrm{SO}_{4}, \mathrm{FeSO}_{4}, \mathrm{~K}_{2} \mathrm{CrO}_{7}$, Amonium Asetat, $\mathrm{HCl}$, Selenium Mixture, $\mathrm{NaOH}, \mathrm{H}_{3} \mathrm{BO}_{3}, \mathrm{KH}\left(\mathrm{IO}_{3}\right)_{2}$ dan bahan-bahan lainnya.

\section{Metode Penelitian}

Penelitian ini menggunakan Rancangan Acak Kelompok (RAK) non Faktorial dengan 3 ulangan dan terdiri dari 7 (tujuh) perlakuan sehingga terdapat 21 sampel tanah yang akan diamati dengan dosis kompos yang dipakai yaitu 12,5 kg pohon ${ }^{-1}$. Perlakuan yang digunakan yaitu: Tanpa kompos, kompos T. diversifolia, kompos Lamtoro, kompos Kulit biji kopi, kompos T. diversifolia + Lamtoro, kompos T. diversifolia + Kulit biji kopi dan kompos Lamtoro + Kulit biji kopi. Kompos diaplikasikan pada tanaman kopi Arabika berumur 8 tahun, kemudian dilakukan pengambilan sampel tanah setelah 3 bulan dari pengaplikasian kompos. Sampel tanah di analisis di laboratorium untuk mendapatkan hasil. Data hasil analisis kemudian di lakukan pengujian dengan manggunakan uji BNJ pada taraf 5\% untuk melihat pengaruh kompos pada tanah Andisol.

\section{Prosedur Kerja}

\section{Penentuan Objek Penelitian}

Penentuan objek diawali dengan melakukan survei lapangan lalu menentukan lokasi atau kebun kopi sebagai tempat pengaplikasian pupuk kompos. Setelah menentukan lokasi penelitian selanjutnya mencari dan menetapkan tanaman kopi umur 8 tahun atau tanaman kopi yang berumur seragam sebagai sampel penelitian, kemudian melakukan seleksi dan menetapkan 21 sampel tanaman kopi berumur seragam pada satu lokasi atau kebun dan diberi tanda atau label. Titik-titik koordinat sampel tanaman dapat dilihat pada Tabel 1.

\section{Aplikasi Pupuk Kompos}

Kompos diaplikasikan dengan cara membenamkan kompos melingkari tanaman kopi pada kedalaman $15 \mathrm{~cm}$ dari permukaan tanah. lingkaran lubang kompos dibuat dengan melihat kanopi kopi terpendek, kemudian pada saat pengaplikasian kompos di campur dengan tanah dari hasil galian sampai merata. Dosis yang diberikan adalah $12.5 \mathrm{~kg}$ pohon $^{-1}$ (ICRRI, 2008). Pengaplikasian dilakukan pada ke 21 sampel tanaman yang telah ditetapkan dan diberi label sesuai perlakuan.Setelah dibenamkan, tanaman kopi yang telah di beri kompos dibiarkan sampai tiga bulan dengan pengontrolan gulma yang tumbuh disekitar tanaman kopi selanjutnya barulah dilakukan pengamatan. Sebelumnya dilakukan analisis terhadap sifat kimia kompos yaitu kandungan $\mathrm{N}$-total, $\mathrm{P}_{2} \mathrm{O}_{5}, \mathrm{~K}_{2} \mathrm{O}$ dan $\mathrm{C} / \mathrm{N}$ rasio. 
Tabel 1. Titik Koordinat Sampel Tanaman Kopi.

\begin{tabular}{|c|c|c|c|}
\hline \multirow{2}{*}{ Perlakuan } & \multicolumn{3}{|c|}{ Blok } \\
\hline & I & II & III \\
\hline \multirow{2}{*}{$\mathrm{P} 0$} & $0,4^{\mathrm{O}} 45^{\prime} 56,5^{\prime \prime} \mathrm{LU}$ & $0,4^{\mathrm{O}} 45^{\prime} 55,4^{\prime \prime} \mathrm{LU}$ & $0,4^{\mathrm{O}} 45^{\prime} 55,9^{\prime \prime} \mathrm{LU}$ \\
\hline & $0,96^{\circ} 44^{\prime} 28,6^{\prime \prime} \mathrm{BT}$ & $0,96^{\circ} 44^{\prime} 28,4^{\prime \prime} \mathrm{BT}$ & $0,96^{\circ} 44^{\prime} 28,0^{\prime \prime} \mathrm{BT}$ \\
\hline \multirow{2}{*}{ P1 } & $0,4^{\mathrm{O}} 45^{\prime} 56,3^{\prime \prime} \mathrm{LU}$ & $0,4^{\mathrm{O}} 45^{\prime} 55,7 ” \mathrm{LU}$ & $0,4^{\mathrm{O}} 45^{\prime} 56,0 ” \mathrm{LU}$ \\
\hline & $0,96^{\mathrm{O}} 44^{\prime} 28,6^{\prime \prime} \mathrm{BT}$ & $0,96^{\mathrm{O}} 44^{\prime} 28,5^{\prime \prime} \mathrm{BT}$ & $0,96^{\mathrm{O}} 44^{\prime} 27,9^{\prime \prime} \mathrm{BT}$ \\
\hline \multirow{2}{*}{ P2 } & $0,4^{\mathrm{O}} 45^{\prime} 56,2^{\prime \prime} \mathrm{LU}$ & $0,4^{\mathrm{O}} 45^{\prime} 55,8^{\prime \prime} \mathrm{LU}$ & $0,4^{\mathrm{O}} 45^{\prime} 56,0^{\prime \prime} \mathrm{LU}$ \\
\hline & $0,96^{\circ} 44^{\prime} 28,3^{\prime \prime} \mathrm{BT}$ & $0,96^{\circ} 44^{\prime} 28,4^{\prime \prime} \mathrm{BT}$ & $0,96^{\circ} 44^{\prime} 28,0^{\prime \prime} \mathrm{BT}$ \\
\hline \multirow{2}{*}{ P3 } & $0,4^{\mathrm{O}} 45^{\prime} 56,5^{\prime \prime} \mathrm{LU}$ & $0,4^{\circ} 45^{\prime} 55,7 ” \mathrm{LU}$ & $0,4^{\mathrm{O}} 45^{\prime} 55,9 ” \mathrm{LU}$ \\
\hline & $0,96^{\circ} 44^{\prime} 28,4^{\prime \prime} \mathrm{BT}$ & $0,96^{\circ} 44^{\prime} 28,3^{\prime \prime} \mathrm{BT}$ & $0,96^{\circ} 44^{\prime} 28,0^{\prime \prime} \mathrm{BT}$ \\
\hline \multirow{2}{*}{ P4 } & $0,4^{\mathrm{O}} 45^{\prime} 56,2^{\prime \prime} \mathrm{LU}$ & $0,4^{\mathrm{O}} 45^{\prime} 55,5^{\prime \prime} \mathrm{LU}$ & $0,4^{\mathrm{O}} 45^{\prime} 55,9^{\prime \prime} \mathrm{LU}$ \\
\hline & $0,96^{\circ} 44^{\prime} 28,4^{\prime \prime} \mathrm{BT}$ & $0,96^{\circ} 44^{\prime} 28,4^{\prime \prime} \mathrm{BT}$ & $0,96^{\circ} 44^{\prime} 28,1^{\prime \prime} \mathrm{BT}$ \\
\hline \multirow{2}{*}{ P5 } & $0,4^{\circ} 45^{\prime} 56,2 " \mathrm{LU}$ & $0,4^{\circ} 45^{\prime} 55,6^{\prime \prime} \mathrm{LU}$ & $0,4^{\circ} 45^{\prime} 56,1^{\prime \prime} \mathrm{LU}$ \\
\hline & $0,96^{\circ} 44^{\prime} 28,6^{\prime \prime} \mathrm{BT}$ & $0,96^{\circ} 44^{\prime} 28,5^{\prime \prime} \mathrm{BT}$ & $0,96^{\circ} 44^{\prime} 28,2^{\prime \prime} \mathrm{BT}$ \\
\hline \multirow{2}{*}{ P6 } & $0,4^{\mathrm{O}} 45^{\prime} 56,3^{\prime \prime} \mathrm{LU}$ & $0,4^{\mathrm{O}} 45^{\prime} 55,5^{\prime \prime} \mathrm{LU}$ & $0,4^{\mathrm{O}} 45^{\prime} 55,99^{\prime} \mathrm{LU}$ \\
\hline & $0,96^{\circ} 44^{\prime} 28,5^{\prime \prime} \mathrm{BT}$ & $0,96^{\circ} 44^{\prime} 28,5^{\prime \prime} \mathrm{BT}$ & $0,96^{\circ} 44^{\prime} 28,2^{\prime \prime} \mathrm{BT}$ \\
\hline
\end{tabular}

\section{Penyiapan Sampel Tanah dan Parameter Pengamatan}

Pengambilan sampel tanah dilakukan setelah tiga bulan pengaplikasian kompos ke tanah. Pengambilan sampel tanah dilakukan pada lima titik mengelilingi tanaman kopi pada setiap perlakuan. Sebelum pengambilan sampel tanah, permukan tanah dibersihkan dari kotoran atau rerumputan yang tumbuh diatasnya. Kemudian dilakukan pemboran tanah pada lima titik bagian dalam lingkaran lubang kompos secara acak. Selanjutnya tanah dimasukkan kedalam kantong plastik dan diberi label. Tanah yang diambil dikompositkan terlebih dahulu untuk setiap perlakuan kemudian dilakukan analisis di laboratorium. Parameter sifat kimia tanah yang akan diamati di laboratorium adalah kandungan hara N, P dan K. Metode yang digunakan untuk analisis tanah dapat dilihat pada Tabel 2.

Tabel 2. Parameter Pengamatan

\begin{tabular}{ll}
\hline Sifat Kimia & Metode \\
\hline N- Total & Kjeldhal \\
P- Tersedia & Bray II \\
K- dd & Ekstraksi $\mathrm{NH}_{4} \mathrm{OA}_{\mathrm{C}} \mathrm{pH} 7$ \\
\hline
\end{tabular}

\section{HASIL DAN PEMBAHASAN}

\section{Analisis Kompos}

Hasil analisis beberapa jenis kompos yang digunakan pada penelitian ini dapat dilihat pada Tabel 3.

Tabel 3. Hasil Analisis Beberapa Jenis Kompos yang digunakan

\begin{tabular}{lcccccc}
\hline & \multicolumn{6}{c}{ Jenis kompos } \\
\cline { 2 - 7 } $\begin{array}{c}\text { Parameter } \\
\text { Pengamatan }\end{array}$ & $\begin{array}{c}\text { T. diversifolia } \\
\left(\mathrm{P}_{1}\right)\end{array}$ & $\begin{array}{c}\text { Lamtoro } \\
\left(\mathrm{P}_{2}\right)\end{array}$ & $\begin{array}{c}\text { Kulit biji } \\
\text { kopi }\left(\mathrm{P}_{3}\right)\end{array}$ & $\begin{array}{c}\text { T. diversifolia } \\
+ \text { Lamtoro } \\
\left(\mathrm{P}_{4}\right)\end{array}$ & $\begin{array}{c}\text { T. diversifolia } \\
+ \text { Kulit biji } \\
\text { kopi } \\
\left(\mathrm{P}_{5}\right),\end{array}$ & $\begin{array}{c}\text { Lamtoro }+ \\
\text { Kulit biji } \\
\text { kopi }\left(\mathrm{P}_{6}\right) .\end{array}$ \\
\hline $\mathrm{N}_{2}$-total $(\%)$ & 1.60 & 2.25 & 1.16 & 2.05 & 1.13 & 1.60 \\
$\mathrm{P}_{2} \mathrm{O}_{5}(\%)$ & 0.86 & 0.45 & 0.08 & 0.43 & 0.12 & 0.17 \\
$\mathrm{~K}_{2} \mathrm{O}(\%)$ & 1.81 & 1.49 & 0.90 & 1.83 & 1.57 & 1.41 \\
$\mathrm{C} / \mathrm{N}(\%)$ & 13.21 & 14.24 & 21.06 & 13.88 & 22.59 & 14.08 \\
\hline $\mathrm{S}$ & & & & & &
\end{tabular}

Sumber: Hifnalisa et al. (2020) 


\section{N-Total Tanah akibat Perlakuan Berbagai Jenis Kompos}

Hasil sidik ragam menunjukkan bahwa perlakuan beberapa kompos berpengaruh sangat nyata terhadap N-total tanah Andisol. Nilai N-total tanah akibat perlakuan beberapa kompos dapat dilihat pada Tabel 4 .

Tabel 4. Rata-Rata N-total Tanah akibat Perlakuan Berbagai Jenis Kompos

\begin{tabular}{llc}
\hline \multicolumn{1}{c}{ Jenis kompos } & $\begin{array}{c}\text { N-Total } \\
(\%)\end{array}$ & Kriteria \\
\hline Tanpa Kompos $\left(\mathrm{P}_{0}\right)$ & $0.20 \mathrm{a}$ & Rendah \\
T. diversifolia $\left(\mathrm{P}_{1}\right)$ & $0.33 \mathrm{~b}$ & Sedang \\
Lamtoro $\left(\mathrm{P}_{2}\right)$ & $0.31 \mathrm{~b}$ & Sedang \\
Kulit biji kopi $\left(\mathrm{P}_{3}\right)$ & $0.29 \mathrm{ab}$ & Sedang \\
T. diversifolia + Lamtoro $\left(\mathrm{P}_{4}\right)$ & $0.32 \mathrm{~b}$ & Sedang \\
T. diversifolia + Kulit biji kopi $\left(\mathrm{P}_{5}\right)$ & $0.33 \mathrm{~b}$ & Sedang \\
Lamtoro + Kulit biji kopi $\left(\mathrm{P}_{6}\right)$. & $0.30 \mathrm{~b}$ & Sedang \\
\hline BNJ $(0.05)$ & 0.09 & - \\
\hline
\end{tabular}

Keterangan : Angka yang diikuti oleh huruf yang sama tidak berbeda nyata pada taraf BNJ (0.05)

Tabel 4 menunjukkan bahwa penggunaan kompos $\mathrm{T}$. diversifolia, Lamtoro, $\mathrm{T}$. diversifolia + Lamtoro, T. diversifolia + Kulit biji kopi, dan kompos Lamtoro + Kulit biji kopi berbeda nyata terhadap Kontrol, tetapi tidak berbeda nyata terhadap kompos Kulit biji kopi. Nilai N-total tanah tertinggi terdapat pada perlakuan T. diversifolia dan perlakuan kompos T. diversifolia + Kulit biji kopi yang tidak berbeda nyata dengan perlakuan kompos Lamtoro, kompos Kulit biji kopi, kompos T. diversifolia + Lamtoro dan pada perlakuan kompos Lamtoro + Kulit biji kopi.

Pemberian kompos dapat meningkatkan kandungan Nitrogen Andisol sehingga mengakibatkan adanya pergeseran kelas kriteria $\mathrm{N}$-total tanah dari kelas rendah pada kontrol menjadi kelas sedang pada semua perlakuan kompos. Hal ini dikarenakan kadar Nitrogen yang terkandung dalam kompos yang digunakan memiliki nilai yang tinggi yaitu $1.13-2.25 \%$. Kandungan Nitrogen pada kompos berasal dari proses penguraian bahan organik oleh organisme-organisme yang hidup di dalamnya. Hal ini sesuai dengan penelitian Yuniarti et al. (2008) yang menyatakan bahwa pemberian kompos dapat meningkatkan kandungan Nitrogen tanah dari $0.24 \%$ menjadi $0.25 \%$. Nilai Nitrogen tanah di pengaruhi oleh proses dekomposisi bahan organik, nilai Nitrogen yang rendah pada kontrol dikarenakan tanah Andisol didominasi oleh alofan yang dapat melindungi bahan organik sehingga bahan organik sulit terurai.

\section{P-Tersedia Tanah akibat Perlakuan Berbagai Jenis Kompos}

Hasil sidik ragam menunjukkan bahwa perlakuan beberapa kompos berpengaruh sangat nyata terhadap P-tersedia tanah Andisol. Nilai P-tersedia tanah akibat perlakuan beberapa kompos dapat dilihat pada Tabel 5.

Tabel 5 menunjukkan bahwa nilai rata-rata P-tersedia tanah setelah di beri kompos menunjukkan adanya perbedaan yang nyata terhadap kontrol. Nilai P-tersedia tanah tertinggi terdapat pada perlakuan kompos $\mathrm{T}$. diversifolia yang tidak berbeda nyata dengan perlakuan kompos yang lainnya. Hal ini dikarenakan $\mathrm{P}$ pada kompos memiliki kandungan yang tinggi berkisaran $0.08-0.86 \%$ dan juga dikarenakan pada Andisol unsur hara P mudah terikat oleh mineral dan unsur lainnya sehingga menjadi tidak tersedia bagi tanaman, dengan adanya pemberian kompos tersedianya makanan bagi mikroorganisme. Perombakan bahan organik oleh mikroorganisme menghasilkan asam-asam organik yang berperan untuk mengikat Alofan dan melepaskan unsur hara P sehingga menjadi tersedia bagi tanaman (Hifnalisa et al., 2017). 
Tabel 5. Nilai P-tersedia Tersedia Tanah akibat Perlakuan Berbagai Jenis Kompos

\begin{tabular}{lcc}
\hline \multicolumn{1}{c}{ Jenis kompos } & $\begin{array}{c}\text { P-Tersedia } \\
\left(\mathrm{mg} \mathrm{kg}^{-1}\right)\end{array}$ & Kriteria \\
\hline Tanpa Kompos $\left(\mathrm{P}_{0}\right)$ & $2.00 \mathrm{a}$ & Rendah \\
T. diversifolia $\left(\mathrm{P}_{1}\right)$ & $14.43 \mathrm{~b}$ & Tinggi \\
Lamtoro $\left(\mathrm{P}_{2}\right)$ & $14.17 \mathrm{~b}$ & Tinggi \\
Kulit biji kopi $\left(\mathrm{P}_{3}\right)$ & $12.52 \mathrm{~b}$ & Tinggi \\
T. diversifolia + Lamtoro $\left(\mathrm{P}_{4}\right)$ & $12.42 \mathrm{~b}$ & Tinggi \\
T. diversifolia + Kulit biji kopi $\left(\mathrm{P}_{5}\right)$ & $11.93 \mathrm{~b}$ & Tinggi \\
Lamtoro + Kulit biji kopi $\left(\mathrm{P}_{6}\right)$. & $11.32 \mathrm{~b}$ & Tinggi \\
\hline BNJ $(0.05)$ & 3.24 & - \\
\hline Ken
\end{tabular}

Keterangan : Angka yang diikuti oleh huruf yang sama tidak berbeda nyata pada taraf BNJ (0.05)

Akibat pemberian kompos terjdinya interaksi terhadap P-tersedia tanah yaitu kandungan P-tersedia pada tanah meningkat secara signifikan dan merubah kelas kriteria dari rendah menjadi tinggi. Menurut Hifnalisa et al. (2017) ketersediaan unsur hara P sangat rendah pada Andisol, dikarenakan Andisol merupakan tanah yang terbentuk dari bahan vulkanik yang mengandung beberapa mineral salah satunya mineral Alofan yang dapat mengikat $\mathrm{P}$ sehingga $\mathrm{P}$ menjadi tidak tersedia bagi tanaman.

\section{Kalium Dapat Dipertukarkan (K-dd) Tanah akibat Perlakuan Berbagai Jenis Kompos}

Hasil sidik ragam menunjukkan bahwa perlakuan beberapa kompos berpengaruh sangat nyata terhadap K-dapat dipertukarkan (K-dd) tanah Andisol. Nilai K-dd akibat perlakuan beberapa kompos dapat dilihat pada Tabel 6 .

Tabel 6. Nilai K-dd Tanah akibat Perlakuan Berbagai Jenis Kompos

\begin{tabular}{lcl}
\hline \multicolumn{1}{c}{ Jenis kompos } & $\begin{array}{c}\text { K-dd } \\
\left(\mathrm{cmol} \mathrm{kg}^{-1}\right)\end{array}$ & Kriteria \\
\hline Tanpa Kompos $\left(\mathrm{P}_{0}\right)$ & $0.30 \mathrm{a}$ & Sedang \\
T. diversifolia $\left(\mathrm{P}_{1}\right)$ & $1,57 \mathrm{~b}$ & Sangat Tinggi \\
Lamtoro $\left(\mathrm{P}_{2}\right)$ & $0.68 \mathrm{ab}$ & Tinggi \\
Kulit biji kopi $\left(\mathrm{P}_{3}\right)$ & $0.72 \mathrm{ab}$ & Tinggi \\
T. diversifolia + Lamtoro $\left(\mathrm{P}_{4}\right)$ & $0.79 \mathrm{~b}$ & Tinggi \\
T. diversifolia + Kulit biji kopi $\left(\mathrm{P}_{5}\right)$ & $0.93 \mathrm{~b}$ & Tinggi \\
Lamtoro + Kulit biji kopi $\left(\mathrm{P}_{6}\right)$. & $0.75 \mathrm{ab}$ & Tinggi \\
\hline BNJ $(0.05)$ & 0.47 & - \\
\hline Keterangan : Angka yang diikuti oleh huruf yang sama tidak berbeda nyata pada taraf BNJ $(0.05)$
\end{tabular}

Tabel 6 menunjukkan bahwa penggunaan kompos T. diversifolia, kompos T. diversifolia + Lamtoro, kompos T. diversifolia + Kulit biji kopi berbeda nyata terhadap kontrol, tetapi tidak berdeba nyata terhadap perlakuan kompos Lamtoro, kompos Kulit biji kopi dan kompos Lamtoro + Kulit biji kopi. Data menunjukkan bahwa adanya peningkatan K-dd tanah akibat perlakuan penambahan kompos. Penambahan kompos di tanah juga mengakibatkan adanya pergeseran kelas kriteria K-dd tanah dari kelas sedang pada kontrol menjadi sangat tinggi pada kompos T. diversifolia dan tinggi di lima perlakuan lainnya. Hal ini dikarenakan kompos yang digunakan dalam penelitian ini memiliki kandungan $\mathrm{K}$ yang tinggi dengan kisaran nilai antara $0.90-1.83 \%$. Menurut SNI 19-7030-2004 nilai batas minimum K pada pupuk organik yaitu $0.20 \%$. Setyowati et al. (2018) menyatakan bahwa kompos tithonia mengandung $0.63 \% \mathrm{~K}$ yang diaplikasikan pada tanaman kol. Hasil penelitian yang telah dilakukan oleh Sudjatmiko et al. (2018) penggunaan bahan organik dapat menunjukkan dinamika kandungan K-dd tanah yang selalu berubah setiap waktu dan pada jenis tanaman yang berbeda. Pengaplikasian pupuk 
organik mengindikasikan adanya peningkatan sifat kimia tanah salah satunya yaitu K-dd (Anggita et al., 2018).

\section{KESIMPULAN}

Pemberian kompos T. diversifolia, kompos Lamtoro, kompos Kulit biji kopi, kompos $T$. diversifolia + Lamtoro, kompos T. diversifolia + Kulit biji kopi dan kompos Lamtoro + Kulit biji kopi dengan dosis $12,5 \mathrm{~kg}$ pohon $^{-1}$ dapat meningkatkan kandungan hara $\mathrm{N}$-total, P-tersedia dan K-dd pada tanah Andisol. Kompos yang mampu mensuplai hara N, P, K lebih banyak pada tanah Andisol untuk tanaman kopi Arabika adalah kompos T. diversifolia.

\section{DAFTAR PUSTAKA}

Anggita, T., Muktamar, Z dan Fahrurozi. (2018). Improvement of selected soil chemical properties and potassium uptake by mung bean after aplication of liquid organic fertilizer in ultisol. Terra. 1(1): 1-7.

Badan Standarisasi Nasional (BSN). SNI 19-7030-2004. Spesifikasi Kompos dari Sampah Organik Domestik. Jakarta.

Dinas Perkebunan Provinsi Aceh. 2013. Prospek Pengembangan Kopi Arabika Gayo Di Kabupaten Aceh Tengah dan Bener Meriah. Disbun. Aceh.

Fatmalasari M., F.E. Prasmatiwi dan N. Rosanti. 2016. Analisis manfaat sertifikasi indonesian organic farm certification (inofice) terhadap keberlanjutan usahatani kopi organik di Kecamatan Air Hitam Kabupaten Lampung Barat. JIIA. 4(1): 30-39.

Harada, Y. 1990. Composting and aplication of animal waste. ASPAC. Food and Fertilizer Technology Center. 311: 20-31.

Hifnalisa., Asmarlaili, S., T. Sabrina dan T. C. Nisa. 2017. P status in andisol and P content in arabica coffee seedling leaves due to the application of phosphate providing microorganisms and organic matters in Bener Meriah district. International Journal of Scientific and Technology Research. 6(9): 59-63.

Hifnalisa., Y. Jufri dan Manfarizah. 2020. Pemanfaatan Bahan Organik Insitu Untuk Meningkatkan Kandungan Hara Tanah Andisol dan Tanaman Kopi Arabika yang dikelola Secara Organik di Kabupaten Bener Meriah. Fakultas Pertanian Universitas Syiah Kuala. Banda Aceh.

Indonesian Coffee and Cocoa Research Institute. 2008. Panduan Budidaya dan Pengelolaan Kopi Arabika Gayo. Jember. Jawa Timur.

Menteri Pertanian Republik Indonesia. 2019. Keputusan Menteri Pertanian Republik Indonesia. Menteri Pertanian Republik Indonesia. Jakarta.

Setyowati, N., Sudjamiko, S., Muktamar, Z., Fahrurozi, F., Chozin, M and Simatupang, P. 2018. Growth and yield responses of cauliflower on tithonia (Tithonia diversifolia) compost under organic farming practices. International Jurnal of Agricultural Technology. 14(7). 1905-1914.

Sudjamiko, S., Muktamar, Z., Chozin, M., Setyowati, N. dan Fahrurozi, F. 2017. Changes in Chemical properties of soil in an organic agriculture syistem. Universitas of Bengkulu. Bengkulu.

Sutedjo, M. M., A. G. Kartasapoetra dan R. S. Sastroatmodjo. 1996. Mikro Biologi Tanah. PT. Rhineka Cipta. Jakarta.

Tantri, T., A. A. N. Supadma dan I. D. M. Arthagama. (2016). Uji kualitas beberapa pupuk kompos yang beredar di kota Denpasar. Jurnal Agroekoteknologi Tropika. 5(1): 5262. 
Yuniarti, Anni., M. Damayani dan D. M. Nur. The Effect of Organic and N, P, K Fertilizers on Organic C, Total N, C/N, N Uptake, and Yields od Black Rice on Inceptisols. Jurnal Pertanian Presisi. 3: 90-105. 